\title{
Multi-chimera states in FitzHugh-Nagumo oscillators
}

\author{
Philipp Hövel ${ }^{1,2^{*}}$, Iryna Omelchenko ${ }^{1,2}$ \\ From Twenty Second Annual Computational Neuroscience Meeting: CNS*2013 \\ Paris, France. 13-18 July 2013
}

Chimera states are spatio-temporal patterns of synchrony and disorder observed in homogeneous oscillatory media with nonlocal coupling. They are characterized by coexistence of distinct spatial regions with regular synchronized and irregular incoherent motion. Initially discovered for phase oscillators, chimera states have been also found in systems of nonlocally coupled discrete maps [1], timecontinuous chaotic systems [2] and have been recently realized in experiments [3].

We demonstrate the existence of chimera states for neural oscillators [4]. In detail, we investigate the cooperative dynamics of nonlocally coupled neural populations modeled by FitzHugh-Nagumo systems, where each individual system displays oscillatory local dynamics described by a fast activator and slow inhibitor variable. Applying a phase-reduction technique we show that off-diagonal nonlocal coupling is a crucial factor for the appearance of chimera states. In the considered configuration, this off-diagonal coupling is realized by a rotational coupling matrix that mixes input of the activator and inhibitor and that is conveniently described by the coupling phase as a single control parameter. We analyze the stability of chimera states in the parameter space of the system and discuss mechanisms of transitions between different chimera types.

Surprisingly, we find that for increasing coupling strength classical chimera states undergo transitions from one to multiple domains of incoherence. Then patches of synchronized dynamics appear within the incoherent domain giving rise to a multi-chimera state. We find that, depending on the coupling strength and range, different multi-chimeras arise in a transition from classical chimera states. The additional spatial modulation is due to strong

\footnotetext{
* Correspondence: phoevel@physik.tu-berlin.de

${ }^{1}$ Institut für Theoretische Physik, Technische Universität Berlin, Berlin, 10623, Germany
}

Full list of author information is available at the end of the article coupling interaction and thus cannot be observed in simple phase-oscillator models.

\section{Acknowledgements}

This work is supported by the Federal Ministry of Education and Research (BMBF), Germany (grant no. 01GQ1001B).

\section{Author details}

${ }^{1}$ Institut für Theoretische Physik, Technische Universität Berlin, Berlin, 10623, Germany. ${ }^{2}$ Bernstein Center for Computational Neuroscience, HumboldtUniversität zu Berlin, Berlin, 10115, Germany.

Published: 8 July 2013

\section{References}

1. Omelchenko I, Maistrenko Yu, Hövel P, Schöll E: Loss of coherence in dynamical networks: spatial chaos and chimera states. Phys Rev Lett 2011, 106:234102-1-234102-4.

2. Omelchenko I, Riemenschneider R, Hövel P, Maistrenko Yu, Schöll E: Transition from spatial coherence to incoherence in coupled chaotic systems. Phys Rev E 2012, 85:026212-1-026212-9.

3. Hagerstrom AM, Murphy TE, Roy R, Hövel P, Omelchenko I, Schöll E: Experimental observation of chimeras in coupled-map lattices. Nature Physics 2012, 8:658-661.

4. Omelchenko I, Omel'chenko OE, Hövel P, Schöll E: Multi-chimera states in FitzHugh-Nagumo oscillators. 2013, arXiv, 1212.3190.

doi:10.1186/1471-2202-14-S1-P303

Cite this article as: Hövel and Omelchenko: Multi-chimera states in FitzHugh-Nagumo oscillators. BMC Neuroscience 2013 14(Suppl 1):P303.

Submit your next manuscript to BioMed Central and take full advantage of:

- Convenient online submission

- Thorough peer review

- No space constraints or color figure charges

- Immediate publication on acceptance

- Inclusion in PubMed, CAS, Scopus and Google Scholar

- Research which is freely available for redistribution

Submit your manuscript at www.biomedcentral.com/submit
() Biomed Central
C Biomed Central

(c) 2013 Hövel and Omelchenko; licensee BioMed Central Ltd. This is an Open Access article distributed under the terms of the Creative Commons Attribution License (http://creativecommons.org/licenses/by/2.0), which permits unrestricted use, distribution, and reproduction in any medium, provided the original work is properly cited. 